\title{
Correlative ex situ and Liquid-Cell TEM Observation of Bacterial Cell Membrane Damage Induced by Rough Surface Topology
}

This article was published in the following Dove Press journal: International Journal of Nanomedicine

\author{
David J Banner (D) \\ Emre Firlar (iD) ${ }^{1,2}$ \\ Justas Jakubonis \\ Yusuf Baggia (D) \\ Jodi K Osborn (D) \\ Reza Shahbazian-Yassar (iD ${ }^{2}$ \\ Constantine M Megaridis (iD) ${ }^{2}$ \\ Tolou Shokuhfar (D) ${ }^{1,2}$ \\ 'Department of Bioengineering, \\ University of Illinois at Chicago, Chicago, \\ IL 60607, USA; ${ }^{2}$ Department of \\ Mechanical and Industrial Engineering, \\ University of Illinois at Chicago, Chicago, \\ IL 60607, USA
}

Correspondence: Tolou Shokuhfar

Department of Bioengineering (MC 063),

University of Illinois at Chicago, 85 I

S. Morgan St, SEO 218, Chicago, IL 60607, USA

Tel $+\mid$ 3/2 996-2335

Fax + 312 996-529|

Email tolou@uic.edu
Background: Nanoscale surface roughness has been suggested to have antibacterial and antifouling properties. Several existing models have attempted to explain the antibacterial mechanism of nanoscale rough surfaces without direct observation. Here, conventional and liquid-cell TEM are implemented to observe nanoscale bacteria/surface roughness interaction. The visualization of such interactions enables the inference of possible antibacterial mechanisms. Methods and Results: Nanotextures are synthesized on biocompatible polymer microparticles (MPs) via plasma etching. Both conventional and liquid-phase transmission electron microscopy observations suggest that these MPs may cause cell lysis via bacterial binding to a single protrusion of the nanotexture. The bacterium/protrusion interaction locally compromises the cell wall, thus causing bacterial death. This study suggests that local mechanical damage and leakage of the cytosol kill the bacteria first, with subsequent degradation of the cell envelope.

Conclusion: Nanoscale surface roughness may act via a penetrative bactericidal mechanism. This insight suggests that future research may focus on optimizing bacterial binding to individual nanoscale projections in addition to stretching bacteria between nanopillars. Further, antibacterial nanotextures may find use in novel applications employing particles in addition to nanotextures on fibers or films.

Keywords: liquid TEM, graphene liquid cell, antibacterial nanopatterns, antibacterial surface topology, antibacterial microparticles

\section{Introduction}

Antibacterial treatments are frequently implemented in modern medicine, agriculture, and antimicrobial textiles. ${ }^{1,2}$ Bacteria are, however, capable of developing resistance to many antibacterial treatments. ${ }^{3,4}$ Conventional antibiotics typically act by preventing the upkeep of the cell wall, interfering with the bacterial metabolism, or by inhibiting the synthesis of nucleic acids or proteins. ${ }^{5}$ Antibiotics may also depolarize the cell membrane, allowing ion influx. ${ }^{6}$ This change in ion concentration can kill bacteria. ${ }^{7}$ Antibiotic resistance occurs through limiting uptake of the antibiotic, removal of the antibiotic from within the bacteria, inactivation of the antibiotic through chemical modification or hydrolysis, or modification of the antibiotic's target. ${ }^{8,9}$ In gram-negative bacteria, the outer plasma membrane provides intrinsic protection against the uptake of many antibiotics. ${ }^{10}$ Antibiotics primarily depend on the presence of porin proteins in the plasma membrane. ${ }^{11}$ These porin proteins facilitate the transport of hydrophilic antibiotics across the cell envelope. ${ }^{11}$ 
Mutations in the porin proteins may prevent the transportation of antibiotics. ${ }^{11}$ Bacteria may also reduce the number of porins. ${ }^{11}$ In contrast, gram-positive bacteria lack the outer plasma membrane and are less likely to limit the uptake of antibiotics. ${ }^{12}$ Gram-positive bacteria thus primarily depend on removal of the antibiotic, destruction of the antibiotic, or inactivation of the antibiotic via chemical modification. ${ }^{5}$ Alternatively, bacteria may alter the target of the antibiotic to prevent the antibiotic effects. ${ }^{5}$

Three general approaches to battle antibiotic-resistant bacteria exist: 1) continued development of conventional antibiotics, to which bacteria continue to adapt, 2) sterilization techniques using chemical agents, such as bleach, other harsh chemicals, or heating and cleaning of surfaces; such approaches have limited medical applications, require continuous reapplication, and may have detrimental environmental ramifications. 3) Novel fundamentally-different antibacterial treatments that rely on silver or specific surface topologies. ${ }^{13-19}$ To this end, bacteria were shown to develop resistance to silver treatments. ${ }^{20,21}$ Silver may also present an ecological hazard similar to that posed by chemical or antibiotic treatments. ${ }^{22}$ Regardless of whether an antibacterial treatment features an antibiotic drug, strong chemical, or silver, introduction of substances toxic to bacteria may be inherently caustic and induce environmental damage. ${ }^{16,23}$

Antibacterial surface topologies were first observed in nature. Cicada wings and dragonfly wings exhibit nanotextures which induce bacterial death and reduce bacterial fouling. ${ }^{24-27}$ These antibacterial nanotextures may be synthesized on a variety of biodegradable, non-toxic, and nonpathogenic materials without the presence of any bactericidal chemical or elemental agent. ${ }^{28}$ In previous works, Serrano et al explored nanotexturing of biomedical sutures, ${ }^{28}$ which showed reduced bacterial attachment, suggesting the sutures would be less likely to transmit infections prior to implantation. ${ }^{28}$ However, nanostructured cicada wings were previously shown to kill bacteria with a physical mechanism rather than by preventing bacterial adhesion. ${ }^{26}$

The bactericidal property of nanopillar surface topologies has been proposed to occur through several mechanisms: Pogodin et al proposed that bacteria bind to the top of nanopillars. ${ }^{26}$ The bacteria then attempt to bind below the surface and are consequently stretched between the nanopillars. ${ }^{26}$ This stretching of the cell membrane supposedly causes rupture of the cell wall and induces bacterial death. ${ }^{26}$ In both gram-negative and gram-positive bacteria, the cell wall includes a layer of peptidoglycan, which provides mechanical support. ${ }^{29}$ In gram-positive bacteria, the cell envelope includes the outer cell wall, an intermediate periplasmic space, and an interior plasma membrane. ${ }^{29}$ In gram-negative bacteria, the cell envelope includes an outer lipopolysaccharide and protein layer, an intermediate periplasmic space, a middle cell wall, a second periplasmic space, and an interior plasma membrane. ${ }^{29}$ Linklater et al proposed another mechanism, in which the bacteria induce mechanical forces on the surface of nanopillars upon binding. ${ }^{30}$ These forces then deflect the nanopillars, which then induce strain on the bacteria upon relaxation of the pillars. ${ }^{30}$ This strain damages the cell wall and induces the observed cell death. ${ }^{30}$ While nanopillar surfaces were experimentally shown via traditional fluorescent light microscopy and scanning electron microcopy (SEM) to induce bacterial death, the mechanism of bactericidal activity was mathematically inferred in both Linklater et al and Pogodin et al rather than demonstrated experimentally. ${ }^{26,30}$ In another mechanism, Michalska et al proposed that black silicon nanopillars directly penetrate the cell wall of the bacterium. ${ }^{31}$ However, Linklater et al later suggested that the bacterial death observed in Michalska et al occurred via the strain mechanism. ${ }^{30,31}$

Additional studies have focused on mathematical modeling of bacteria/nanotexture interaction. ${ }^{32-34}$ By necessity, these mathematical models included assumptions such that the stiffness of the bacteria may be modeled as a singlelayer of peptidoglycan, that deformation of the bacterial cell wall does not induce other metabolic processes (eg, apoptosis) through programmed cell death, and that the bacteria binding to the surface occurs through purely physics-based methods, such as hydrophobic interactions and Van der Waals forces. The initial bacteria/surface contact is indeed dependent on physical factors, such as surface charge and wettability (hydrophilicity/hydrophobicity). ${ }^{35-39}$ However, bacteria/surface binding occurs in a second stage, wherein adhesion forces far exceed the forces in the initial contact period and are dominated by multiple adhesion proteins and attachment pili. ${ }^{35-39}$ Bacterial binding of nanotextures is an active process and depends on the metabolic rate, which confirms the active role of protein adhesion in bacteria/ nanotexture binding. ${ }^{40}$ Thus, while mathematical models are insightful and may prove useful for offering predictions, experimental verification of these mathematical models is also essential. Further, multiple bactericidal mechanisms are possible and may not be mutually exclusive.

Observational non-mechanistic studies provide direct evidence of the efficacy of a treatment on a particular 
bacterial strain. However, bacterial strains vary in size, stiffness, and metabolic processes. ${ }^{41}$ Due to these bacterial differences, observational studies require testing antibacterial treatments iteratively against multiple strains to produce a generalized inference of the real-world applications of any antibacterial approach. ${ }^{31}$ Experimental studies of the E.coli/nanotexture interaction mechanisms are thus needed to complement existing observational studies and mathematical models. Here, both conventional transmission electron microscopy (TEM) and liquid-phase TEM are implemented to observe the mechanism of bacterial death. Liquid-phase TEM allows for high-resolution nanoscale observations of the $E$. coli/nanotexture interactions without requiring preservation of the sample. E. coli $\mathrm{K} 12$ is well-characterized in literature as a model organism and was thus chosen for this investigation. ${ }^{42,43}$ In contrast to previous works on films or larger fibers, here poly (lactic-co-glycolic acid) (PLGA) microparticles (MPs) are nanotextured and are shown to have an antibacterial effect on E. coli in liquid media. ${ }^{26,28,30,31}$ PLGA is biocompatible, biodegradable, low-cost, FDA-approved, and may be functionalized with other antibacterial treatments to produce a combined antibacterial effect if desired. ${ }^{44,45}$ Suspensions containing E. coli and nanotextured PLGA MPs were imaged in TEM via both conventional TEM and liquid-phase TEM via graphene liquid cells (GLCs) to observe bacterial death and structural changes in E. coli.

\section{Materials and Methods Bacteria Culturing}

E. coli $\mathrm{K} 12$ were commercially purchased (Escherichia coli (Migula) Castellani and Chalmers, ATCC ${ }^{\circledR} 29425^{\mathrm{TM}}$ ). Starter cultures were preserved in 50\% glyceraldehyde and 50\% phosphate buffered saline (PBS) and frozen at $-80^{\circ} \mathrm{C}$ as previously described. ${ }^{46} \mathrm{E}$. coli was cultured in $50 \mathrm{~mL}$ lysogeny broth (LB) at $37.5^{\circ} \mathrm{C}$ on an orbital shaker at 100RPM as previously described. $^{47}$

\section{PLGA Microparticle Etching}

PLGA MPs were commercially purchased (Degrdex ${ }^{\circledR}$ PLGA microspheres, LG500). The particles varied between several nanometers to several micrometers in diameter. The PLGA MPs were then dispersed in DI water and sonicated for 5 mins. The PLGA MP suspension was then dropcast in $10 \mu \mathrm{L}$ quantities onto approximately $5 \times 5 \mathrm{~cm}$ copper sheets and allowed to dry completely for at least $12 \mathrm{hrs}$. The PLGA-covered copper sheets were then plasma etched via the method described by
Serrano et al. ${ }^{28}$ The particles were etched using a South Bay PC150 plasma etcher under 200 ppm oxygen at $100 \mathrm{~W}$ in 1 min increments, with 2 mins between each increment to prevent heating of the sample. After etching, the copper sheets were cut into strips and placed in microcentrifuge tubes containing $1 \mathrm{~mL}$ sterile PBS and sonicated for 5 mins to remove the PLGA MPs from the copper sheets.

\section{SEM of PLGA MPs}

PLGA MPs on copper after plasma etching were gold sputter-coated for $1 \mathrm{~min}$ and imaged in SEM via a RAITH100 eLine EBL at $2 \mathrm{kV}$ to $3 \mathrm{kV}$ with working distances of $13 \mathrm{~mm}$ to $20 \mathrm{~mm}$.

\section{AgNP Solution Preparation}

Silver NPs (AgNPs) were commercially purchased and added to sterile PBS. The suspensions were then sonicated to facilitate suspension of the AgNPs, and exposed to UV light to sterilize the sample.

\section{Colony Counting}

$E$. coli were cultured in LB broth to the stationary phase of $E$. coli growth. Ten microliters were then extracted from each $E$. coli culture to determine viability prior to the addition of antibacterial materials. PLGA MPs and AgNPs were added to the appropriate $E$. coli samples, which were then immediately returned to the incubator. The extracted samples were diluted to $10^{-2}, 10^{-4}$, and $10^{-6}$, and plated on LB agar plates, as described previously. ${ }^{48}$ The colony counting procedure was repeated at $4 \mathrm{hrs}$ and $8 \mathrm{hrs}$ after the addition of the antibacterial or control samples to the $E$. coli culture to observe bacterial death over time. This procedure was repeated six times to produce statistically valid data. The results were analyzed via Student's $t$-test. ${ }^{49}$

\section{Conventional TEM Imaging}

E. coli was cultured to the stationary phase at which point PLGA MPs etched for 2 mins were added, incubated an additional 20 mins, and then fixed for imaging with conventional TEM. The stationary phase refers to the phase of bacterial population growth at which the total population is constant. ${ }^{50}$ Bacteria and the antibacterial agent were centrifuged to isolate the sample as a pellet, with the LB broth removed. The samples were then preserved in resin via glutaraldehyde and osmium fixing and staining, as per Feng et al. ${ }^{51}$ This conventional TEM method includes microtoming the samples to produce cross-sectional 2D slices for imaging. ${ }^{52}$ Some of the rod-shaped, bacilli $E$. coli may thus appear 
circular due to the orientation of these bacteria within the $2 \mathrm{D}$ slice. ${ }^{53}$ A JEOL 1220 TEM was used for image acquisition. TEM images were false-colored for clarity. The original, unaltered images are included in the SI.

\section{In situ TEM Imaging}

$E$. coli was cultured to stationary phase in LB broth. PLGA MPs etched for 2 mins were added to the solution and incubated for an additional 20 mins. The LB broth was then removed via centrifugation and the sample rehydrated in PBS. Approximately $1 \mu \mathrm{L}$ of the solution was placed on a graphene-coated TEM grid and then covered with another graphene-coated grid to produce a graphene sandwich. Textor et al provided a detailed review of this GLC synthesis process. ${ }^{54}$ The incident electron dose varied between $3 \times 10^{9} \mathrm{~Gy} / \mathrm{s}$ to $6 \times 10^{10} \mathrm{~Gy} / \mathrm{s}$ throughout the experiment. A JEOL 1220 TEM was used for imaging. TEM images were false-colored for clarity. The original, unaltered images are included in the $\underline{\mathrm{SI}}$.

\section{Results and Discussion}

In the first step, the PLGA MPs were plasma-treated to produce nanotextures on their surface. The MPs were plasma etched for 1, 2, and 5 mins to induce different surface roughness (see Material and Methods, Figure 1A-C). The PLGA MPs were imaged via SEM to observe the surface topology (Figure 1D-G). The PLGA MPs show minimal nanotexturing in particles etched for $1 \mathrm{~min}$, while at 2 mins these nanotextures are deeper and more pronounced. At 5 mins of plasma etching, the sample is highly damaged leaving behind damaged, disordered PLGA. Particles etched for 2 mins, with the roughest surface morphology, were selected for antibacterial testing.
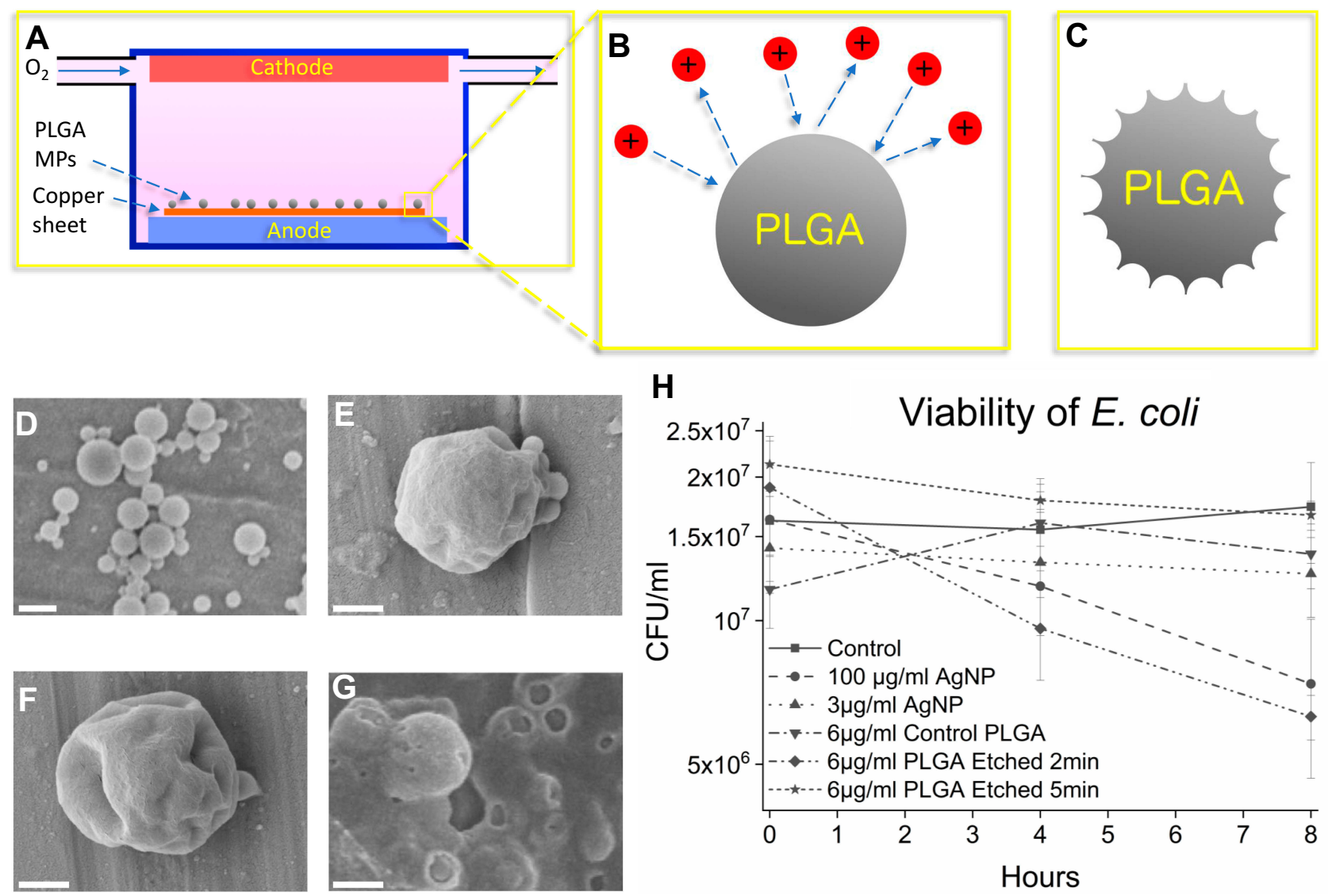

Figure I Schematic of plasma etching of PLGA MPs (A-C), SEM imaging of the control PLGA MPs and the plasma-etched PLGA MPs (D-G) and viability graph of E. coli control and in the presence of antibacterial agents $(\mathbf{H})$. In $(\mathbf{A})$ oxygen flows in low concentration ( $200 \mathrm{ppm}$ volume) through a charged environment to create free radicals $(\mathbf{B})$ which etch the surface, leaving behind rough MPs (C). In (D) unetched particles show smooth surface morphology. In (E) the PLGA MPs show mild dimpling of the surface after I min of plasma etching. In (F) the PLGA MPs etched for 2 mins show more pronounced, sharp patterns as opposed to the PLGA MPs shown in (D) and (E). Finally, in (G) 5 mins of etching severely damaged the MPs, reducing the PLGA to primarily amorphous PLGA aggregations. The bactericidal efficacy of PLGA MPs and AgNPs are compared in (H) where control and bacteria treated with $3 \mu \mathrm{g} / \mathrm{mL} \mathrm{AgNPs}$ do not show decreased CFU/mL, while the $100 \mu \mathrm{g} / \mathrm{mL} \mathrm{AgNPs} \mathrm{samples} \mathrm{show} \mathrm{decreased} \mathrm{viability.} \mathrm{The} \mathrm{error} \mathrm{bars} \mathrm{in}(\mathbf{H})$ represent the standard error. The unetched PLGA does not exhibit a statistically significant bactericidal effect, nor does the PLGA etched for 5 mins. However, the PLGA etched for 2 mins, which features rough MP surfaces, does exhibit a statistically significant bactericidal effect. The scale bar is I $\mu \mathrm{m}$ in (D), and $500 \mathrm{~nm}$ in (E), (F), and (G). 
In the next step, the bacterial activities of treated and untreated PLGA MPs were studied and compared with AgNPs. Unetched smooth PLGA MPs, PLGA MPs etched for 2 mins, and PLGA MPs etched for 5 mins were added in concentrations of $6 \mu \mathrm{g} / \mathrm{mL}$ to separate $E$. coli cultures at the stationary growth phase (see Material and Methods, Figure 1H). Additionally, AgNPs, known to have bactericidal effects, were added to separate LB broth solutions in concentrations of $3 \mu \mathrm{g} / \mathrm{mL}$ AgNPs and $100 \mu \mathrm{g} / \mathrm{L} \mathrm{AgNPs}$ to create positive controls (see Material and Methods). ${ }^{21}$ The results show the PLGA MPs etched for 2 mins lowered the viability of $E$. coli by approximately $64 \%(\mathrm{p}<0.05)$ as compared to controls, while the $100 \mu \mathrm{g} / \mathrm{mL}$ AgNPs exhibited bactericidal effects which lowered the viability of $E$. coli by approximately $57 \%(\mathrm{p}<0.10)$ (Figure $1 \mathrm{H})$. The E. coli sample containing $3 \mu \mathrm{g} / \mathrm{mL}$ AgNP may not have shown a statistically significant antibacterial effect (Figure $1 \mathrm{H}$ ) due to the large size of the AgNPs used in this work, which may reduce the bactericidal efficiency of AgNPs as compared to smaller AgNPs used in other studies (Figure 1H). ${ }^{55}$ The control, smooth PLGA MPs did not kill E. coli, in agreement with previous findings that PLGA is non-toxic. ${ }^{44}$ The highly damaged amorphous PLGA MPs likewise do not exhibit any bactericidal effect, suggesting that the plasma etching process does not alter the chemistry or surface properties of the PLGA MPs to produce bactericidal effects. Further, the increased surface area on the highly damaged PLGA etched for 5 mins would be expected to increase the bactericidal effect if bacterial death was due to a chemical effect rather than the rough surface topology. Only the PLGA MPs etched for 2 mins with the rough nanotextured surface kill bacteria, to which only the nanotextures are unique, thus indicating that it is the nanotextures that kill E. coli.

Direct mechanical damage to the cell wall compromises the cell envelope permeability and induces cell death. ${ }^{26}$ Metabolically mediated cell wall degradation may occur due to a cessation of metabolic cell wall maintenance or by the production of intracellular autolysins which actively break down the cell wall. ${ }^{56}$ Further, escape of the bacterial cytosol, the fluid within bacteria, and a decrease in volume are indicative of bacterial death. ${ }^{57}$ Conventional light microscopy therefore uses fluorescent dyes to determine the integrity of the cell wall regardless of the mechanism of bacterial death. ${ }^{58}$ However, TEM allows nanoscale observation of the cell envelope and MPs and thus does not require fluorescent dyes since cell-wall damage can be directly deserved. ${ }^{51,59}$

Nanotextured PLGA MP/bacteria surface interactions were examined via conventional TEM as shown in Figure 2 (see Material and Methods) and Figure S1. In this figure, a PLGA MP has rough nanotexture and uneven edges as observed with SEM (Figure 1). As shown in Figure 2A and B (progressive magnification) (also in Figure S1), the MP has a surface protrusion inside an adjacent bacterium. The location of the surface protrusion suggests that the MP sharp features pierced the cell envelope of the bacterium, including the outer membrane, peptidoglycan layer, and inner membrane. Piercing the cell envelope would produce local cell damage and lysis of the bacterium. ${ }^{26,30,31,60}$ The absence of the bacterial cell envelope in Figure 2B indicates that this damage was sufficient to stop the metabolic maintenance of the cell envelope or produce apoptosis. ${ }^{60}$ In contrast to mathematical modeling in previous
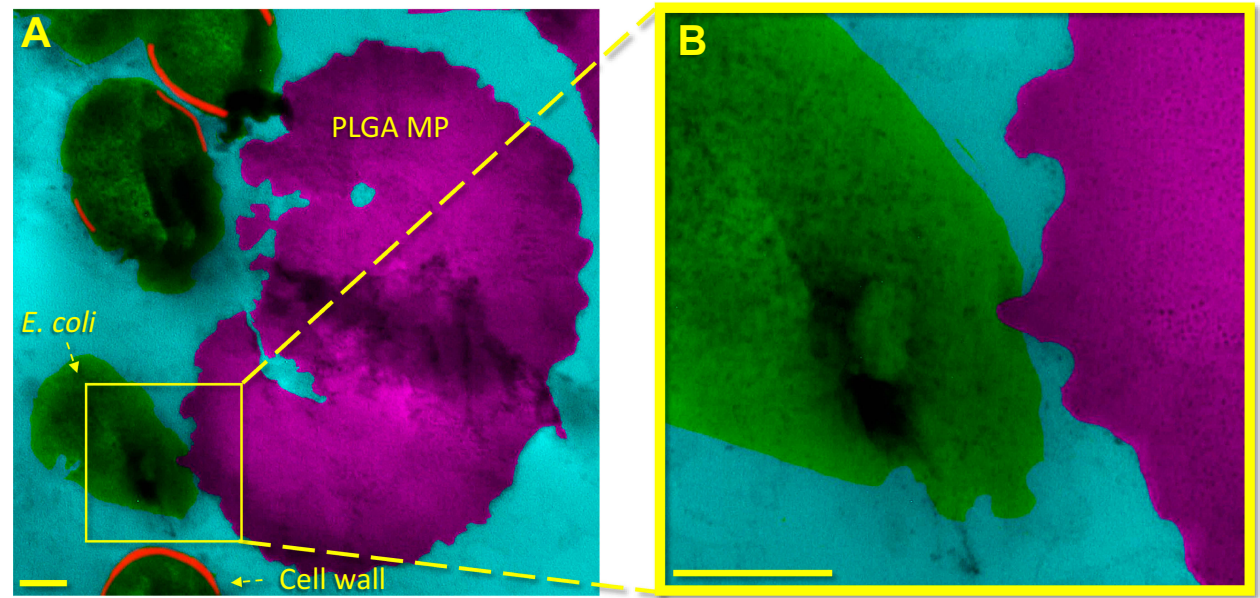

Figure 2 Bacterial death is induced by rough MP topography as observed in a cross-sectional image obtained via conventional TEM. In (A) and (B) low to high magnifications of surface interaction between an E. coli and a rough PLGA particle etched for 2 mins is shown. A sharp peak on the PLGA particle appears to have penetrated the E. coli bacterium cell envelope. The area bracketed in (A) is shown at higher magnification in (B). The scale bars in (A) and (B) are $200 \mathrm{~nm}$. 
works, in Figure 2 the E. coli is not stretched between nanopillars but rather is in contact with a single sharp protrusion, which appears to have been directly penetrated the cell surface (Figure S1). ${ }^{26,30,32-34}$

E. coli and PLGA MPs etched for 2 mins were then encapsulated together in GLCs (Figures 3 and S2). In GLCs, a liquid sample is encapsulated between two layers of graphene (see Material and Methods). ${ }^{61-64}$ The graphene layers are impermeable to liquid matter, fully encasing the sample, and allow transmission of the electron beam through the sample. The graphene also dissipates energy, which reduces undesired effects of the beam exposure (SI, Liquid-TEM Imaging). ${ }^{57}$ Previous works have shown that the effects of changes in pressure, temperature, free radical generation, and exposure to the electron beam itself are non-significant under low electron doses for large samples, such as those containing E. coli, as implemented here (SI notes). ${ }^{57,59,61,65-76}$ Thus, previous works indicate that $E$. coli 1 ) maintain their metabolic processes, 2) maintain their cell envelopes, and 3) continue to undergo binary fission within liquid-phase TEM. ${ }^{57,59,61,65-76}$

Liquid-phase TEM (Figures 3 and $\underline{\text { S2}}$ ) provides further evidence of the penetration of nanoprotrusions in E.coli, as also observed forensically with conventional TEM (Figures 2 and $\underline{\mathrm{S} 1}$ ). The cell envelope of the bacterium immediately adjacent to a rough PLGA MP is highly damaged and shows escape of the bacterium's cytosol. In contrast, areas distal to the PLGA MP surface protrusion show smooth, undamaged cell envelopes. The localization of cell damage to the site of bacterium/PLGA MP interaction indicates that the bacterium was not killed by general metabolic factors, which would cause diffuse damage throughout the bacterium cell envelope. Bacterial death thus must have occurred due to the localized damage produced by the $E$. coli/surface interaction.

Gram-negative bacteria, including $E$. coli, contain peptidoglycan cell walls approximately $2 \mathrm{~nm}$ to $8 \mathrm{~nm}$ in thickness. In contrast, gram-positive bacteria have cell wall thicknesses from approximately $20 \mathrm{~nm}$ to $35 \mathrm{~nm} .^{41,77}$ Peptidoglycan has been considered to provide the structural support and is a primary contributor to the mechanical properties of bacteria. $^{78}$ The thickness of the peptidoglycan layer might be intuitively expected to reflect the stiffness of bacteria. In contrast to this expectation, initial experimental studies reported that gram-negative bacteria exhibit an average Young modulus of approximately $30 \mathrm{MPa}$ while gram-positive bacteria exhibit a Young modulus of $20 \mathrm{MPa}^{41}$ However, further studies showed that the Young modulus varies significantly depending on the bacterial species, growth medium, preparation method, dry or wet state, and measurement method, with previously reported Young modulus values between $0.05 \mathrm{MPa}$ and $769 \mathrm{MPa} .{ }^{41,79}$ This variation in mechanical properties reflects cell wall variations in proteins, phospholipids, teichoic acids, lipoteichoic acids, and differences in peptidoglycanpeptidoglycan binding or interactions. ${ }^{80}$ Peptidoglycans consist of alternating sugar moieties, $\beta-(1,4)$ linked $\mathrm{N}$-acetylglucosamine and $\mathrm{N}$-acetylmuramic acid, which are then attached to a peptide chain. ${ }^{81,82}$ While the sugar moieties are highly conserved between bacterial species, the attached peptide chains are bacterial strain-specific and vary significantly in peptide chain length and amino acid composition. ${ }^{41}$
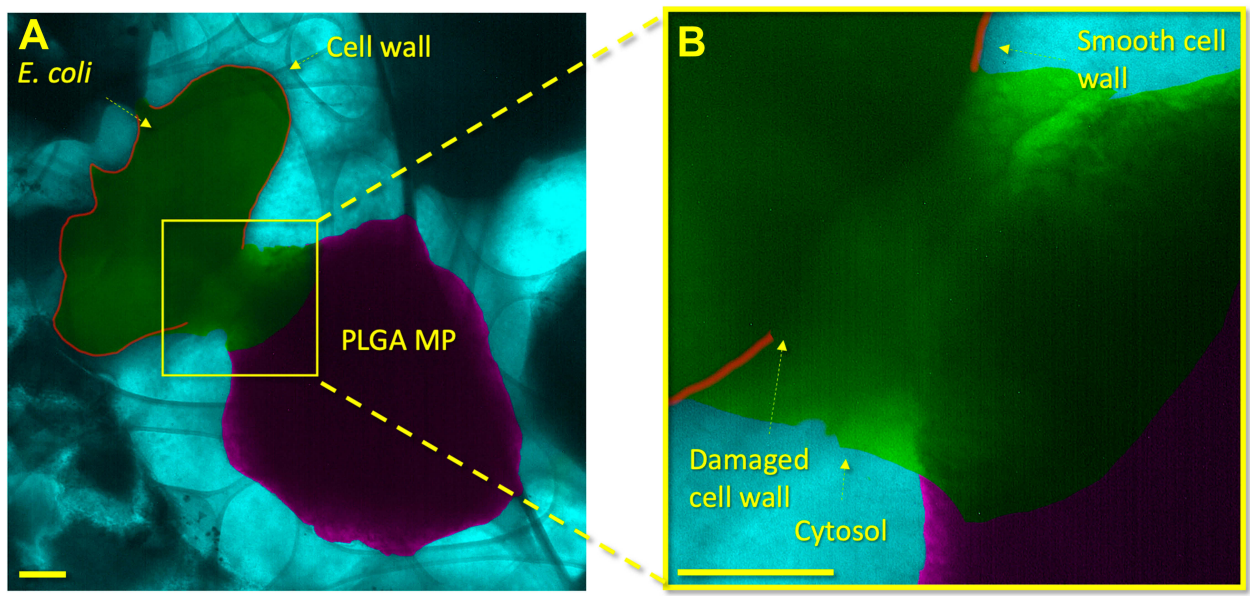

Figure 3 GLC encapsulation of E. coli and PLGA MPs shows localized damage to the cell envelope of the bacterium. In (A), a lower-magnification image shows an overview of the E. coli and PLGA MP. In (B), a higher magnification shows the PLGA MP and bacterium in close proximity. The cell wall proximal to the PLGA MP shows damage with a shape similar to the adjacent MP. A high contrast liquid indicates the cytosol of the bacterium, which clearly identifies the death of the bacterium. The cytosol has a distinct contrast from the PBS medium due to the proteins, glycans, and other bacterial components within it. Other areas of the $E$. coli cell wall are smooth and show no damage or degradation. The scale bars in (A) and (B) are $200 \mathrm{~nm}$. 
Peptidoglycans may be monomers or cross-linked as dimers or trimers, with linkages between a variety of amino acid residues. ${ }^{83,84}$ The variation in peptide chains and the activity of crosslinking proteins produces unique chain crosslinking. ${ }^{85,86}$ The degree and type of peptidoglycan crosslinking are thus highly positively correlated with the stiffness of the bacteria. ${ }^{80}$ Some bacteria may also contain actin-like filaments that form a rudimentary cytoskeleton. ${ }^{87}$ These actinlike filaments may influence the mechanical properties of bacteria, including their stiffness. ${ }^{87}$ In short, the thickness of the peptidoglycan layer and the gram-positive/gram-negative classification are not sufficient to establish the mechanical properties of bacteria. ${ }^{41}$ This suggests that the bactericidal nature of nanoscale surface topologies may also be effective in gram-positive bacteria, since the cell wall of such bacteria may be comparable to $E$. coli. ${ }^{41}$

The deformation of the bacterial cell wall thus depends not on simple physical forces and the thickness of the peptidoglycan layer, but on the Young modulus of the bacterial cell wall and the attachment forces of the bacterial adhesion proteins. E. coli was previously shown to exhibit a Young modulus of $22 \mathrm{MPa}^{88}$ This suggests the attachment pressure of $E$. coli exceeds this value to produce strain within the cell wall to produce the damage shown in Figures 2 and 3 (Figures S1 and S2). The bactericidal mechanism of antibacterial nanotextures observed here and supported by literature is illustrated schematically in Figure 4. First, simple physical forces, eg, hydrophobic/hydrophilic interactions, bring the $E$. coli into contact with the PLGA particle surface. $^{38,39}$ The adhesion proteins then attach and contract to bind the E. coli to the PLGA surface. ${ }^{38,39}$ However, the protruding fixture on the PLGA surface exerts a local force opposing the adhesion proteins bound to the non-protruding surface (Figures 2,3 and $\underline{\mathrm{S} 1, \mathrm{~S} 2}$ ). This causes stretching in the E. coli cell membrane over the PLGA nanopillar, as experimentally observed here in Figures 2 and 3 (Figures S1 and $\underline{\mathrm{S} 2}$ ) and illustrated in Figure 4A-D, which damages the cell envelope. This damage causes the death of the $E$. coli and leakage of the cytosol localized to the nanotexture projection, as experimentally observed in Figures 3 and $\underline{\mathrm{S} 2}$. This cell
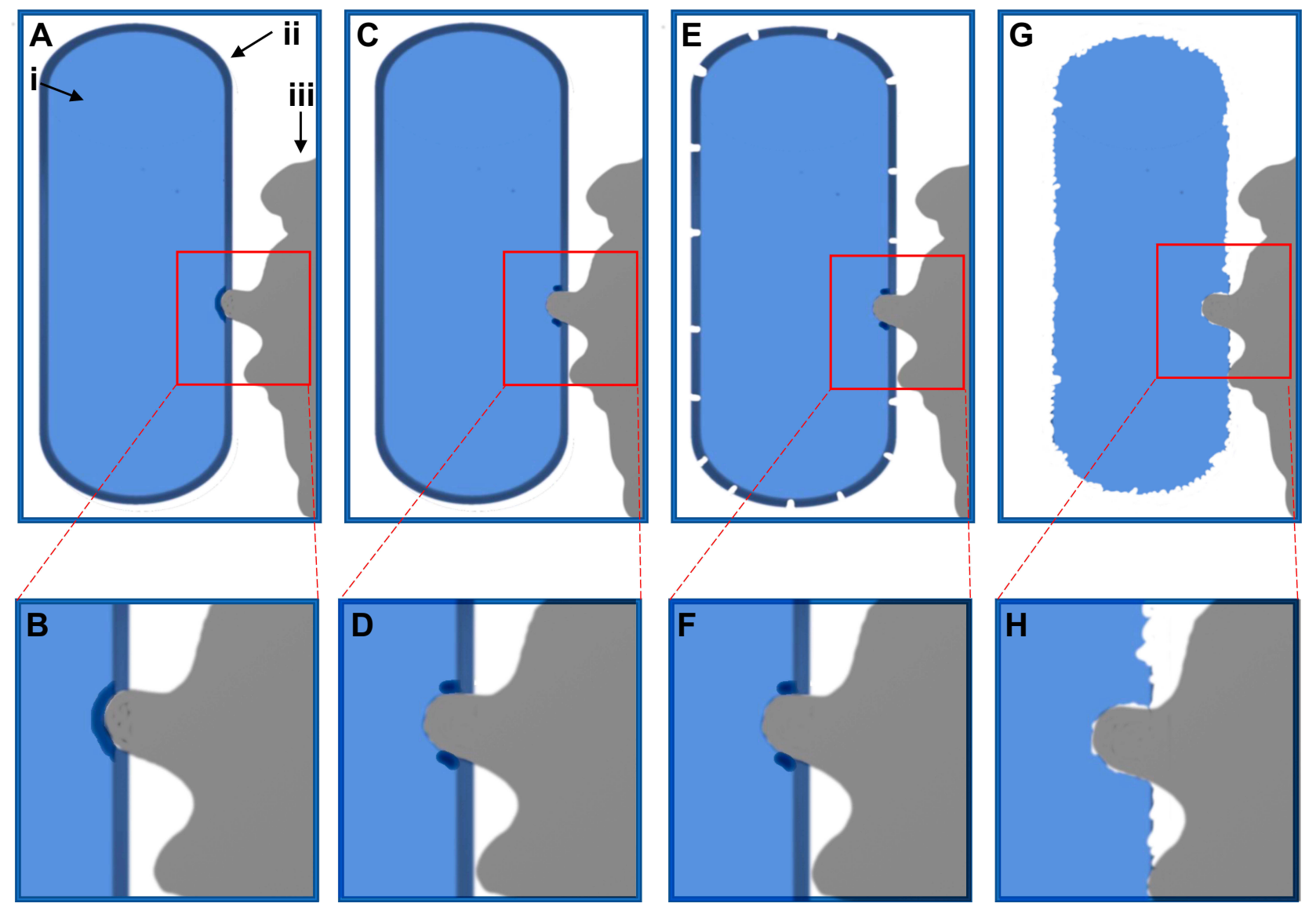

Figure 4 Schematic illustration of bacterial death mechanism. The bacterium is shown in blue on the left side of the image (i), whereas the cell envelope is indicated as a dark blue layer on the outer edge of the bacterium (ii). The PLGA particle is shown in grey on the right-hand side (iii). In (A) and (B) the particle has come into contact and deforms the cell envelope, before breaking it in (C) and (D). This damage then causes degradation of the cell envelope in (E) and (F), before the cell wall disintegrates in $(\mathbf{G})$ and $(\mathbf{H})$. 
death later results in total degradation of the cell envelope due to reduced metabolic cell envelope maintenance or production of autolysis, as experimentally observed in Figure 2 (Figure S1) and illustrated in Figure 4E-H. ${ }^{56}$ Here, a mechanism by which nanoscale surface roughness may kill E. coli K12 has been shown.

\section{Conclusions}

We report rough nanotextured polymer MPs that exhibit antibacterial action. Such MPs have applications distinct from previously designed media, such as antibacterial gels, liquid suspensions, or powders. The nanotextured surface topology of the MPs was shown to be bactericidal via a localized E. coli/ surface interaction mechanism. The MP surface protrusions deform bacterial cell walls to induce bacterial death rather than act by damaging bacterial cell walls via stretching between nanopillars. This cell-wall damage suggests that the attachment pressure exceeded the force required for deformation of the cell wall of the bacterium. The deformation of the cell envelope appears to cause cell lysis and death of the E. coli. Future studies are required to explore the nanoscale interaction of rough surface topology with other types of bacteria, and to further exploit the antibacterial mechanism suggested here. One should be aware that the success rates of liquid-phase TEM experiments are very low. The reproducibility of such liquid-phase TEM tests is also very challenging and needs to be revisited. We believe more careful studies are needed to ensure the bacteria are alive in the TEM environment.

\section{Acknowledgments}

This work was funded by the Nonwovens Institute (North Carolina State Univ. Grant 16-195). T. Shokuhfar and E. Firlar acknowledge NSF CAREER Award \#1564950. Partial support from NSF Award \#1803693 is acknowledged. R. Shahbazian-Yassar's efforts were supported by NSF Award \# 1710049. This work made use of instruments in the Electron Microscopy Core of UIC's Research Resources Center (RRC). The authors would like to thank the University of Illinois at Chicago's Nanotechnology Core Facility of the College of Engineering and the RRC, Vice Chancellor's Office for Research, for its services and instrumentation use. Portions of this work were carried out in the Fluorescence Imaging Core (FIC) of the RRC at UIC.

\section{Disclosure}

The authors report no conflicts of interest in this work.

\section{References}

1. McArthur JV, Tuckfield RC, Baker-Austin C. Antimicrobial textiles. Berlin, Heidelberg: Springer; 2012:135-152.

2. Witte W. Medical consequences of antibiotics use in agriculture. Science. 1998;379(5353):996-997. doi:10.1126/science.279.5353.996

3. Livermore DM, Brown DF. Detection of beta-lactamase-mediated resistance. J Antimicrob Chemother. 2001;48:59-64. doi:10.1093/jac/ 48.suppl_1.59

4. Davies J. Origins and evolution of antibiotic resistance. Microbiologia. 1996;74(3):417-433.

5. Reygaert WC. An overview of the antimicrobial resistance mechanisms of bacteria. AIMS Microbiol. 2018;4(3):482-501. doi:10.3934/ microbiol.2018.3.482

6. Kepplinger B, Morton-Laing S, Seistrup KH, et al. Mode of action and heterologous expression of the natural product antibiotic vancoresmycin. ACS Chem Biol. 2018;13(1):207-214. doi:10.1021/ acschembio. $7 \mathrm{~b} 00733$

7. Cadelis MM, Pike EIW, Kang W, et al. Exploration of the antibiotic potentiating activity of indolglyoxylpolyamines. Eur J Med Chem. 2019;183:111708. doi:10.1016/j.ejmech.2019.111708

8. Cox G, Wright GD. Intrinsic antibiotic resistance: mechanisms, origins, challenges and solutions. Int J Med Microbiol. 2013;303 (6-7):287-292. doi:10.1016/j.ijmm.2013.02.009

9. Chancey ST, Zähner D, Stephens DS. Acquired inducible antimicrobial resistance in Gram-positive bacteria. Future Microbiol. 2012;7:959-978. doi:10.2217/fmb.12.63

10. Epand RM, Walker C, Epand RF, Magarvey NA. Molecular mechanisms of membrane targeting antibiotics. Biochim Biophys Acta Biomembr. 2016;1858(7):980-987. doi:10.1016/j.bbamem.2015.10.018

11. Pagès JM, James CE, Winterhalter $M$. The porin and the permeating antibiotic: a selective diffusion barrier in Gram-negative bacteria. Nat Rev Microbiol. 2008;6(12):893-903. doi:10.1038/nrmicro1994

12. Lambert PA. Cellular impermeability and uptake of biocides and antibiotics in Gram-positive bacteria and mycobacteria. J Appl Microbiol Symp Suppl. 2002;92:46S-54S. doi:10.1046/j.1365-2672.92.5s1.7.x

13. Balaban NQ, Liu J. Evolution under antibiotic treatments: interplay between antibiotic persistence, tolerance, and resistance. In: Lewis $\mathrm{K}$, editor. Persister cells and infectious disease. Cham: Springer International Publishing; 2019:1-17.

14. Durão P, Balbontín R, Gordo I. Evolutionary mechanisms shaping the maintenance of antibiotic resistance. Trends Microbiol. 2018;26 (8):677-691. doi:10.1016/j.tim.2018.01.005

15. Silindir M, Özer AY. Sterilization methods and the comparison of E-beam sterilization with gamma radiation sterilization. Fabad J Pharm Sci. 2009;34:43-53.

16. Alavi M, Rai M. Recent advances in antibacterial applications of metal nanoparticles (MNPs) and metal nanocomposites (MNCs) against multidrug-resistant (MDR) bacteria. Expert Rev Anti Infect Ther. 2019;17(6):419-428. doi:10.1080/14787210.2019.1614914

17. Alavi M, Karimi N, Valadbeigi T. Antibacterial, antibiofilm, antiquorum sensing, antimotility, and antioxidant activities of green fabricated Ag, $\mathrm{Cu}, \mathrm{TiO} 2, \mathrm{ZnO}$, and $\mathrm{Fe} 3 \mathrm{O} 4$ NPs via protoparmeliopsis muralis lichen aqueous extract against multi-drug-resistant bacteria. ACS Biomater Sci Eng. 2019;5(9):4228-4243. doi:10.1021/acsbiomaterials.9b00274

18. Alavi M, Rai M. Recent progress in nanoformulations of silver nanoparticles with cellulose, chitosan, and alginic acid biopolymers for antibacterial applications. Appl Microbiol Biotechnol. 2019;103 (21-22):8669-8676. doi:10.1007/s00253-019-10126-4

19. Alavi M, Nokhodchi A. An overview on antimicrobial and wound healing properties of $\mathrm{ZnO}$ nanobiofilms, hydrogels, and bionanocomposites based on cellulose, chitosan, and alginate polymers. Carbohydr Polym. 2020;227:115349. doi:10.1016/j.carbpol.2019.115349

20. Panáček A, Kvítek L, Smékalová M, et al. Bacterial resistance to silver nanoparticles and how to overcome it. Nat Nanotechnol. 2018;13:65-71. doi:10.1038/s41565-017-0013-y 
21. Randall CP, Gupta A, Jackson N, Busse D, O’Neill AJ. Silver resistance in Gram-negative bacteria: a dissection of endogenous and exogenous mechanisms. J Antimicrob Chemother. 2015;70(4):1073-1046.

22. Panyala NR, Peña-Méndez EM, Havel J. Silver or silver nanoparticles: a hazardous threat to the environment and human health? J Appl Biomed. 2008;6:117-129. doi:10.32725/jab.2008.015

23. Kim S, Choi JE, Choi J, et al. Oxidative stress-dependent toxicity of silver nanoparticles in human hepatoma cells. Toxicol Vitr. 2009;23 (6):1076-1084. doi:10.1016/j.tiv.2009.06.001

24. Kelleher SM, Habimana O, Lawler J, et al. Cicada wing surface topography: an investigation into the bactericidal properties of nanostructural features. ACS Appl Mater Interfaces. 2016;8(24):14966-14974. doi:10. 1021/acsami.5b08309

25. Hasan J, Webb HK, Truong VK, et al. Selective bactericidal activity of nanopatterned superhydrophobic cicada Psaltoda claripennis wing surfaces. Appl Microbiol Biotechnol. 2013;97(20):9257-9262. doi:10.10 07/s00253-012-4628-5

26. Pogodin S, Hasan J, Baulin VA, et al. Biophysical model of bacterial cell interactions with nanopatterned cicada wing surfaces. Biophys $J$ 2013;104(4):835-840. doi:10.1016/j.bpj.2012.12.046

27. Bandara CD, Singh S, Afara IO, et al. Bactericidal effects of natural nanotopography of dragonfly wing on escherichia coli. ACS Appl Mater Interfaces. 2017;9(8):6746-6760. doi:10.1021/acsami.6b13666

28. Serrano C, García-Fernández L, Fernández-Blázquez JP, et al. Nanostructured medical sutures with antibacterial properties. Biomaterials. 2015;52:291-300. doi:10.1016/j.biomaterials.2015.02.039

29. Silhavy TJ, Kahne D, Walker S. The bacterial cell envelope. Cold Spring Harb Perspect Biol. 2010;2(5):a000414. doi:10.1101/cshperspect.a000414

30. Linklater DP, De Volder M, Baulin VA, et al. High aspect ratio nanostructures kill bacteria via storage and release of mechanical energy. ACS Nano. 2018;12(7):6657-6667. doi:10.1021/acsnano.8b01665

31. Michalska M, Gambacorta F, Divan R, et al. Tuning antimicrobial properties of biomimetic nanopatterned surfaces. Nanoscale. 2018;10:6639-6650. doi:10.1039/C8NR00439K

32. Xue F, Liu J, Guo L, Zhang L, Li Q. Theoretical study on the bactericidal nature of nanopatterned surfaces. $J$ Theor Biol. 2015;385:1-7. doi:10.1016/j.jtbi.2015.08.011

33. Ayazi M, Golshan Ebrahimi N, Jafari Nodoushan E. Bacterial adhesion reduction on the surface with a simulated pattern: an insight into Extrand model. Int $J$ Adhes Adhes. 2019;88:66-73. doi:10.1016/j. ijadhadh.2018.10.017

34. Li X. Bactericidal mechanism of nanopatterned surfaces. Phys Chem Chem Phys. 2015;18(2):1311-1316. doi:10.1039/C5CP05646B

35. An YH, Friedman RJ. Concise review of mechanisms of bacterial adhesion to biomaterial surfaces. J Biomed Mater Res. 1998;43:338. doi:10.1002/(ISSN)1097-4636

36. Foster TJ, Geoghegan JA, Ganesh VK, Höök M. Adhesion, invasion and evasion: the many functions of the surface proteins of Staphylococcus aureus. Nat Rev Microbiol. 2014;12(1):49-62. doi:10.1038/nrmicro 3161

37. Elbourne A, Chapman J, Gelmi A, Cozzolino D, Crawford RJ, Truong VK. Bacterial-nanostructure interactions: the role of cell elasticity and adhesion forces. J Colloid Interface Sci. 2019;546:192-210. doi:10.1016/j.jcis.2019.03.050

38. Goulter RM, Gentle IR, Dykes GA. Issues in determining factors influencing bacterial attachment: a review using the attachment of Escherichia coli to abiotic surfaces as an example. Lett Appl Microbiol. 2009;49(1):1-7. doi:10.1111/j.1472-765X.2009.02591.x

39. Tuson HH, Weibel DB. Bacteria-surface interactions. Soft Matter. 2013;9:4368-4380. doi:10.1039/c3sm27705d

40. Köller M, Ziegler N, Sengstock C, Schildhauer TA, Ludwig A. Bacterial cell division is involved in the damage of gram-negative bacteria on a nano-pillar titanium surface. Biomed Phys Eng Express. 2018;4:055002. doi:10.1088/2057-1976/aad2c1
41. Auer GK, Weibel DB. Bacterial cell mechanics. Biochemistry. 2017;56(29):3710-3724. doi:10.1021/acs.biochem.7b00346

42. Blount ZD. The unexhausted potential of E. coli. Elife. 2015;4: e05826. doi:10.7554/eLife.05826

43. Keseler IM, Collado-Vides J, Gama-Castro S, et al. EcoCyc: a comprehensive database resource for Escherichia coli. Nucleic Acids Res. 2005;33:D334-D337. doi:10.1093/nar/gki108

44. Makadia HK, Siegel SJ. Poly lactic-co-glycolic acid (PLGA) as biodegradable controlled drug delivery carrier. Polymers (Basel). 2011;3(3):1377-1397. doi:10.3390/polym3031377

45. Anderson JM, Shive MS. Biodegradation and biocompatibility of PLA and PLGA microspheres. Adv Drug Deliv Rev. 1997;28 (1):5-24. doi:10.1016/S0169-409X(97)00048-3

46. Son MS, Taylor RK. Growth and maintenance of Escherichia coli laboratory strains. Curr Protoc Microbiol. 2012; Chapter 5:Unit5A.4.

47. Sezonov G, Joseleau-Petit D, D’Ari R. Escherichia coli physiology in Luria-Bertani broth. $J$ Bacteriol. 2007;189(23):8746-8749. doi:10.1128/JB.01368-07

48. Breed RS, Dotterrer WD. The number of colonies allowable on satisfactory agar plates. J Bacteriol. 1916;1(3):321-331. doi:10.1128/ JB.1.3.321-331.1916

49. de Winter JCF. Using the student's t-test with extremely small sample sizes. Pract Assess Res Eval. 2013;18(10):1-12.

50. Monod J. The growth of bacterial cultures. Annu Rev Microbiol. 1949;3:371-394. doi:10.1146/annurev.mi.03.100149.002103

51. Feng QL, Wu J, Chen GQ, Cui FZ, Kim TN, Kim JO. A mechanistic study of the antibacterial effect of silver ions on Escherichia coli and Staphylococcus aureus. J Biomed Mater Res. 2000;52(4):662-668. doi:10.1002/1097-4636(20001215)52:4<662::AID-JBM10>3.0 $\mathrm{CO} ; 2-3$

52. Winey M, Meehl JB, O'Toole ET, Giddings TH. Conventional transmission electron microscopy. Mol Biol Cell. 2014;25(3):319-323. doi:10.1091/mbc.e12-12-0863

53. Zhang L, Jiang Y, Ding Y, et al. Mechanistic investigation into antibacterial behaviour of suspensions of $\mathrm{ZnO}$ nanoparticles against $\mathrm{E}$. coli. J Nanoparticle Res. 2010;12:1625-1636. doi:10.1007/s11051009-9711-1

54. Textor M, De Jonge N. Strategies for preparing graphene liquid cells for transmission electron microscopy. Nano Lett. 2018;18 (6):3313-3321. doi:10.1021/acs.nanolett.8b01366

55. Lok C-N, Ho C-M, Chen R, et al. Silver nanoparticles: partial oxidation and antibacterial activities. J Biol Inorg Chem. 2007;12 (4):527-534. doi:10.1007/s00775-007-0208-z

56. Kohanski MA, Dwyer DJ, Collins JJ. How antibiotics kill bacteria: from targets to networks. Nat Rev Microbiol. 2010;8:423-435. doi:10.1038/nrmicro2333

57. Berry V. Impermeability of graphene and its applications. Carbon N Y. 2013;62:1-10. doi:10.1016/j.carbon.2013.05.052

58. Stiefel P, Schmidt-Emrich S, Maniura-Weber K, Ren Q. Critical aspects of using bacterial cell viability assays with the fluorophores SYTO9 and propidium iodide. BMC Microbiol. 2015;15:36. doi:10.1186/s12866-015-0376-x

59. Mohanty N, Fahrenholtz M, Nagaraja A, Boyle D, Berry V. Impermeable graphenic encasement of bacteria. Nano Lett. 2011;11 (3):1270-1275. doi:10.1021/nl104292k

60. Islam MS, Aryasomayajula A, Selvaganapathy PR. A review on macroscale and microscale cell lysis methods. Micromachines. 2017;8(3):83. doi:10.3390/mi8030083

61. Firlar E, Ouy M, Bogdanowicz A, et al. Investigation of the magnetosome biomineralization in magnetotactic bacteria using graphene liquid cell-transmission electron microscopy. Nanoscale. 2019;11 (2):698-705. doi:10.1039/C8NR08647H

62. Wang C, Qiao Q, Shokuhfar T, Klie RF. High-resolution electron microscopy and spectroscopy of ferritin in biocompatible graphene liquid cells and graphene sandwiches. Adv Mater. 2014;26 (21):3410-3414. doi:10.1002/adma.v26.21 
63. Ghodsi SM, Anand S, Shahbazian-Yassar R, Shokuhfar T, Megaridis CM. In situ study of molecular structure of water and ice entrapped in graphene nanovessels. ACS Nano. 2019;13(4):4677-4685. doi:10.1021/acsnano.9b00914

64. Yuk JM, Park J, Ercius P, et al. High-resolution EM of colloidal nanocrystal growth using graphene liquid cells. Science. 2012;336 (6077):61-64.

65. Woehl TJ, Kashyap S, Firlar E, et al. Correlative electron and fluorescence microscopy of magnetotactic bacteria in liquid: toward in vivo imaging. Sci Rep. 2014;4:6854. doi:10.1038/srep06854

66. Kennedy E, Nelson EM, Tanaka T, Damiano J, Timp G. Live bacterial physiology visualized with $5 \mathrm{~nm}$ resolution using scanning transmission electron microscopy. ACS Nano. 2016;10(2):2669-2677. doi:10.1021/acsnano.5b07697

67. Kennedy E, Nelson EM, Damiano J, Timp G. Gene expression in electron-beam-irradiated bacteria in reply to "Live cell electron microscopy is probably impossible." ACS Nano. 2017;11(1):3-7. doi:10.1021/acsnano.6b06616

68. Wang Y, Chen X, Cao H, Deng C, Cao X, Wang P. A structural study of Escherichia coli cells using an in situ liquid chamber TEM technology. J Anal Methods Chem. 2015;2015:829302. doi:10.1155/ 2015/829302

69. Ghodsi SM, Megaridis CM, Shahbazian-Yassar R, Shokuhfar T. Advances in graphene-based liquid cell electron microscopy: working principles, opportunities, and challenges. Small Methods. 2019;3:453001. doi:10.1002/smtd.v3.5

70. Shin D, Park JB, Kim Y-J, et al. Growth dynamics and gas transport mechanism of nanobubbles in graphene liquid cells. Nat Commun. 2015;6:6068. doi:10.1038/ncomms7068

71. Khestanova E, Guinea F, Fumagalli L, Geim AK, Grigorieva IV. Universal shape and pressure inside bubbles appearing in van der Waals heterostructures. Nat Commun. 2016;7:12587. doi:10.1038/ ncomms 12587

72. Gänzle M, Liu Y. Mechanisms of pressure-mediated cell death and injury in Escherichia coli: from fundamentals to food applications. Front Microbiol. 2015;6:599. doi:10.3389/fmicb.2015.00599

73. Grogan JM, Schneider NM, Ross FM, Bau HH. Bubble and pattern formation in liquid induced by an electron beam. Nano Lett. 2014;14 (1):359-364. doi:10.1021/n1404169a

74. Levanduski L, Jaczynski J. Increased resistance of Escherichia coli O157: h7to electron beam following repetitive irradiation at sub-lethal doses. Int J Food Microbiol. 2008;121(3):328-334. doi:10.1016/j. ijfoodmicro.2007.11.009
75. Egerton RF. Control of radiation damage in the TEM. Ultramicroscopy. 2013;127:100-108. doi:10.1016/j.ultramic.2012.07.006

76. Egerton RF. Mechanisms of radiation damage in beam-sensitive specimens, for TEM accelerating voltages between 10 and $300 \mathrm{kV}$. Microsc Res Tech. 2012;75(11):1550-1556. doi:10.1002/jemt.v75.11

77. Beeby M, Gumbart JC, Roux B, Jensen GJ. Architecture and assembly of the Gram-positive cell wall. Mol Microbiol. 2013;88 (4):664-672. doi:10.1111/mmi.2013.88.issue-4

78. Gan L, Chen S, Jensen GJ. Molecular organization of Gram-negative peptidoglycan. Proc Natl Acad Sci. 2008;105(48):18953-18957. doi:10.1073/pnas.0808035105

79. Tuson HH, Auer GK, Renner LD, et al. Measuring the stiffness of bacterial cells from growth rates in hydrogels of tunable elasticity. $\mathrm{Mol}$ Microbiol. 2012;84(5):874-891. doi:10.1111/mmi.2012.84.issue-5

80. Loskill P, Pereira PM, Jung P, et al. Reduction of the peptidoglycan crosslinking causes a decrease in stiffness of the staphylococcus aureus cell envelope. Biophys J. 2014;107(5):1082-1089. doi:10.1016/j. bpj.2014.07.029

81. Vollmer W. Structure and biosynthesis of the Murein (Peptidoglycan) sacculus. In: Ehrmann M, editor. The periplasm. ASM Press;2007:198-213.

82. van Heijenoort J. Formation of the glycan chains in the synthesis of bacterial peptidoglycan. Glycobiology. 2001;11(3):25R-36R. doi:10.10 93/glycob/11.3.25R

83. Vollmer W, Bertsche U. Murein (peptidoglycan) structure, architecture and biosynthesis in Escherichia coli. Biochim Biophys Acta Biomembr. 2008;1778(9):1714-1734. doi:10.1016/j.bbamem.2007.06.007

84. Glauner B, Holtje JV, Schwarz U. The composition of the murein of Escherichia coli. J Biol Chem. 1988;263(21):10088-10095.

85. Snowden MA, Perkins HR. Peptidoglycan cross-linking in Staphylococcus aureus An apparent random polymerisation process. Eur J Biochem. 1990;191(2):373-377. doi:10.1111/ejb.1990.191.issue-2

86. Magnet S, Dubost L, Marie A, Arthur M, Gutmann L. Identification of the L,D-transpeptidases for peptidoglycan cross-linking in Escherichia coli. J Bacteriol. 2008;190(13):4782-4785. doi:10.1128/JB.00025-08

87. Wang S, Arellano-Santoyo H, Combs PA, Shaevitz JW. Actin-like cytoskeleton filaments contribute to cell mechanics in bacteria. Proc Natl Acad Sci. 2010;107(20):9182-9185. doi:10.1073/pnas.0911517107

88. Si F, Li B, Margolin W, Sun SX. Bacterial growth and form under mechanical compression. Sci Rep. 2015;5:11377. doi:10.1038/srep11367
International Journal of Nanomedicine

\section{Publish your work in this journal}

The International Journal of Nanomedicine is an international, peerreviewed journal focusing on the application of nanotechnology in diagnostics, therapeutics, and drug delivery systems throughout the biomedical field. This journal is indexed on PubMed Central, MedLine, CAS, SciSearch ${ }^{\mathbb{R}}$, Current Contents ${ }^{\mathbb{R}} /$ Clinical Medicine, $^{2}$
Journal Citation Reports/Science Edition, EMBase, Scopus and the Elsevier Bibliographic databases. The manuscript management system is completely online and includes a very quick and fair peer-review system, which is all easy to use. Visit http://www.dovepress.com/ testimonials.php to read real quotes from published authors. 